\title{
A REFORMA DO ENSINO MÉDIO E A BASE NACIONAL COMUM CURRICULAR: DO TEMOR À NECESSIDADE DA CIÊNCIA GEOGRÁFICA
}

\author{
Gustavo Henrique Camargo Eufrásio \\ Universidade Federal de Catalão, Instituto de Geografia, Catalão, GO, Brasil. \\ Estudos Interdisciplinares em Gênero, Cultura e Trabalho - DIALOGUS/UFCAT/CNPq \\ gustavocamargo 11@outlook.com
}

\author{
Carmem Lúcia Costa \\ Universidade Federal de Catalão, Instituto de Geografia, Catalão, GO, Brasil. \\ Programa de Pós-Graduação em Geografia, Catalão, GO, Brasil \\ Universidade Federal de Goiás, Programa de Pós-Graduação Interdisciplinar em Direitos Humanos, Goiânia, \\ GO, Brasil. \\ Estudos Interdisciplinares em Gênero, Cultura e Trabalho - DIALOGUS/UFCAT/CNPq \\ clcgeo@gmail.com
}

\begin{abstract}
RESUMO
Este artigo possui como ponto central a discussão do modelo de currículo proposto por meio da Base Nacional Comum Curricular (BNCC), assim como a Reforma do Ensino Médio. $O$ que se busca é apresentar elementos, desde suas constituições até os efeitos que elas promovem para a educação, bem como sobre o lugar da Geografia neste novo cenário. São expostas realidades do estado de Goiás e do município de Catalão-GO a fim de entender a implementação dessas mudanças nas escolas públicas locais. Para concretude deste trabalho foram utilizadas revisões e análises documentais e bibliográficas sobre a área de educação e ensino em Geografia; órgãos responsáveis pelo ensino público foram visitados a fim de acompanhar a implementação da BNCC. Confirma-se, nas reflexões realizadas, uma ligação entre a educação e o capital, além da inferiorização de certas ciências formando sujeitos deficitários crítica e socialmente. Percebe-se que a educação atual está ligada ao processo de (re)produção de desigualdades, baseada no mercado, em que o intuito é instituir um ideal de meritocracia partindo da legitimidade ancorada em um currículo homogeneizado.
\end{abstract}

Palavras-chave: BNCC. Reforma do Ensino Médio. Ensino de Geografia. Catalão.

\section{THE SECONDARY EDUCATION REFORM AND THE BASE NACIONAL COMUM CURRICULAR: FROM FEAR TO NEED FOR GEOGRAPHIC SCIENCE} \section{ABSTRACT}

This research paper has as a central point the discussion about the curriculum model approached through the Base Nacional Comum Curricular (BNCC). Given this understand the construction of this document to the consequences that it brings with the Secondary Education Reform, how to bring this line of thought to meet Geography. These are real exhibitions from Goiás, BR and the city of Catalão-GO, to understand the implementation of these changes in public schools. To carry out this research, documentary and bibliographic analyzes on the area of education and of Geography teaching were used. In the reflections made, understand a relation between education and capital, in addition to the inferiorization of sciences, deficient and worst educationally trained estudents. Where current education is associated with the process of (re)producing inequalities, based on the capitalism, in which the intention it is an institution of meritocracy, based on legitimacy of a homogenized curriculum.

Keywords: BNCC. The Secondary Education Reform. Geography Teaching. Catalão.

\section{INTRODUÇÃO}

A educação no Brasil desde a década de 1990 foi remodelada, desde a gestão ao currículo. Nesse sentido, alterações foram feitas tendo como marco destes acontecimentos a Lei de Diretrizes e Bases da Educação (Lei n. 9.393/ 1996). Yanaguita (2011) explica que o neoliberalismo, enquanto forma protagonista de governo no país, construiu mudanças que - mais de vinte anos depois - são experimentadas na atualidade, em especial, após o golpe de destituição da presidenta Dilma Rousseff em 2016. Nesse contexto, a educação é uma das repartições do Estado que sofre com esses ataques inconstitucionais, materializando medidas em curso e algumas já aprovadas que desmontam a educação pública. Posto isto, foi proposto o

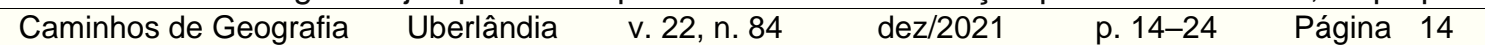


desenvolvimento de uma pesquisa por intermédio do PIBIC/ PROLICEN com apoio do CNPQ/ UFG, entre 2018 e 2019, que gerou trabalhos e divulgação de resultados em âmbito nacional e internacional, entre tantos, este artigo.

Conforme o cenário político vivido entre 2016 e 2018 sob o comando do governo Temer, observa-se que somente no final de 2017 e 2018 proposições políticas para educação foram realizadas, todavia com caminhos contrários ao ideal emancipador de educação proposto por Freire (2005). Diante disso, a Base Nacional Comum Curricular (BNCC, 2018) e a Reforma do Ensino Médio (Lei n. 13.415/ 2017) foram os instrumentos que nos levaram à indagação e à vontade de pesquisar sobre os impactos que os mesmos causarão na sociedade, pois os textos de sustentação podem ser lidos - em conformidade com a exposição de Girotto (2017) - como uma forma de reestruturar as desigualdades, alimentar um ensino tecnicista e deficitário, além de legitimar a meritocracia.

Quando levantamos pontuações como as supracitadas é possível notar que educar e pensar criticamente (cf. PONTUSCHKA, 2007) desaparecem, o que se vê é uma reestruturação no instrumento de alienação dos sujeitos escolares. Essa perversidade que as políticas educacionais contemporâneas possuem é alinhada a uma leitura capitalista proposta por Mészáros (2005), em que a educação é um artifício de mobilização para a construção de uma classe trabalhadora oprimida e cega quanto às correntes que aprisionam nesse limbo classista e dual.

Compreender o conhecimento enquanto poder, alinhado ao pensamento de Vesentini (1989), é o que nos atenta para um olhar cuidadoso a estas duas políticas, em que homogeneizar, compactar e relativizar conteúdos, conhecimentos e ciências são ações que ferem a construção integral dos(as) estudantes. Dito isto, o artigo busca analisar o impacto da BNCC, bem como da Reforma do Ensino Médio, e os efeitos sobre a ciência geográfica, com enfoque ao estado de Goiás e a realidade do munícipio de Catalão.

\section{METODOLOGIA}

Debruçar sobre uma pesquisa que atinge diretamente sujeitos sociais põe em evidência a necessidade de se fazer uso do modo qualitativo de pesquisar. Recorrendo em Pêssoa (2012), ela nos apresenta a viabilidade do estudo qualitativo, "por ser uma abordagem mais interpretativa que se propõe traduzir e expressar o fenômeno estudado, também se constitui em um trabalho laborioso, visto que é necessário registrar as informações, coletar dados, organizá-los e fazer as análises" (MATOS e PESSÔA, 2009, p.282 apud PÊSSOA, 2012, p. 7).

Desta forma, para o desenvolvimento da pesquisa realizamos a revisão bibliográfica e documental, analisando autores e autoras em livros e periódicos que se dedicam aos estudos de educação, das políticas educacionais e do ensino de Geografia, assim, algumas bases que sustentam esse capítulo são: Callai (1995; 2000), Castrogiovanni (2000), Cavalcanti (1998; 2012), Fernandes (1977), Freire (2005), Girotto (2017; 2018), Hooks (2013), Marcuse (1982), Mészáros (2005), Pontuschka (2007), Santos (2003), Saviani (2010), Simões (2017) e Vesentini (1989).

Por se tratar de uma leitura para a compreensão de leis e normatizações para a educação analisamos documentos institucionais do Estado, como a Lei n. 9.394/ 1996, a Lei n. 13.415/ 2017, os Parâmetros Curriculares Nacionais de 1998 e a Base Nacional Comum Curricular e o Documento Curricular do Estado de Goiás. Em um segundo momento da pesquisa direcionamos nosso olhar para as realidades do estado goiano, realizando visitas à Subsecretaria Regional de Educação do Estado de Goiás (em Catalão-GO) e ao Sindicato de Trabalhadores em Educação do Goiás, além de participar de eventos promovidos em prol da BNCC no estado goiano.

\section{RESULTADOS E DISCUSSÃO: BNCC, DESIGUALDADE EDUCACIONAL E O ENSINO EM GEOGRAFIA}

Compreender o espaço escolar é internalizar, no âmbito subjetivo e objetivo das ações e relações, que o mesmo é uma espécie orgânica, fluída, capaz de associar e dissociar as realidades. Partindo desse pressuposto, deve entendê-lo enquanto um espaço protagonizado por tensões que o moldam, em que criam e recriam à maneira que convém a uma maior parcela de força e/ou poder (SANTOS, 1978). Diante disso e trazendo a pesquisa para o contato com as realidades vividas em solo brasileiro, percebemos que a educação e todo seu aporte sofre mudanças que confluem em novas dimensões para se pensar o ato de educar e ensinar, em especial, na esfera pública e gratuita. 
Durante os últimos anos, mais precisamente desde o ano de 1930, três mudanças e/ou reformulações na educação brasileira são fundamentais para compreender o cenário contemporâneo educativo: o governo varguista, a sombria ditadura militar e os governos neoliberais da década de 1990, sendo estes preâmbulos dos movimentos de alteração nos espaços escolares brasileiros atuais.

A partir de 1930 o governo de Getúlio Vargas apresenta um protagonismo frente ao cenário brasileiro de desenvolvimento, sobretudo industrial, Araujo Junior (2020) apresenta que com o estímulo sobre a indústria a qualificação de pessoal se torna necessário para manutenção do trabalho. Deste modo, é instituída a Reforma Capanema, "que estruturou o ensino industrial, reformou o ensino comercial e trouxe mudanças no ensino secundário" (ARAUJO JUNIOR, 2020, p. 31). Outro marco é na Ditadura Militar, através da Lei n. 5.692/ 1971, que reproduz essa profissionalização da educação, "na tentativa de unificar os antigos ensinos primário e médio, eliminando as diferenças entre os ramos secundário (agrícola, industrial e comercial) e normal. Esta Lei trazia a obrigatoriedade da profissionalização a todos os alunos e escolas" (ARAUJO JUNIOR, 2020, p. 31).

A educação para o trabalho é marco evidente nas políticas de Vargas e dos militares, esse relacionamento é encaminhado pelo comando do capital para sua reprodução, como alerta Araujo Junior (2020, p. 32): "A educação, na visão de uma sociedade capitalista, deve buscar ações e políticas que possam suprir a demanda empresarial por mão de obra, qualificada ou semiqualificada". Durante a década de 1990 a educação segue nessa direção, apresentando sob a face do neoliberalismo um avanço do ensino privado como de maior qualidade em relação ao ensino público, além de anunciar a precarização da escola e da carreira docente (ARAUJO JUNIOR, 2020).

Assim, esses três tempos expostos possuem similaridades em que a necessidade de manutenção do capital é colocada sobre a importância da educação enquanto meio emancipatório da sociedade. Deste modo:

a educação, que é dever do Estado, passa a ser gerida de acordo com as noções de produtividade, redução de custos, ganhos de escala, que são os fundamentos do sistema capitalista. A educação, deixa de ser, portanto, um direito do cidadão e se transforma em mercadoria, passível de ser comercializada de acordo com interesses empresariais (ARAUJO JUNIOR, 2020, p. 37).

O que vemos é uma educação afim com o capital, cujas comprovações são possíveis por intermédio de uma pesquisa bibliográfica e documental - diante disso, recorremos às legislaturas e documentações de domínio público que insurgem sobre o processo educativo do Ensino Médio. Indo mais além, utilizamos teóricos e teóricas que se debruçam sobre o estudo e a pesquisa a respeito da educação brasileira e do ensino de Geografia.

Como objetivamos a compreensão do grau de efetividade da Base Nacional Comum Curricular (BNCC) e da Reforma do Ensino Médio frente à Geografia tomamos como base central os dois documentos federais. Assim, foram resgatados seu momento embrionário até a homologação nos âmbitos federais para toda educação básica, bem como sua ligação com o ramo empresarial. Essa construção teórica apresentada é fruto de uma pesquisa de iniciação científica construída por mais de um (1) ano, buscando respaldos teóricos e metodológicos por meio de leituras, participações em eventos, minicursos e apresentações de resultados da pesquisa.

Problemáticas e deficiências na educação brasileira são visíveis seja por meio de censos avaliativos, como o Índice de Desenvolvimento da Educação Básica (IDEB) ou o Programa Internacional de Avaliação de Alunos (PISA). Também podem ser citadas pontualidades evidenciadas por aqueles que atuam no chão da escola como, por exemplo, a dicotomia dos conteúdos e o distanciamento ante o cotidiano, negando uma das teses freireanas para uma educação libertadora (FREIRE, 2005). Um resgate histórico é a chave para o entendimento das políticas para a educação brasileira ocorridas nos últimos cinco anos, afinal, muitas mudanças foram propostas atingindo este setor, três destaques são apresentados a seguir: a aprovação da Emenda Constitucional (EC) ํo 95/ 2016 (responsável pelo congelamento dos gastos públicos durante vinte anos), o sancionamento da Lei no 13.415/ 2017 (reformuladora do Ensino Médio), e a homologação da Base Nacional Comum Curricular (BNCC).

Para entender as mudanças na educação, salientamos que seus efeitos desenvolvem promoções coniventes com o sistema hegemônico vigente, isto é, a lógica do capital legitimando a presença de abismos sociais e fazendo com que se preserve a desigualdade, "as políticas educacionais das nações periféricas são, historicamente, pautadas pelas profundas diferenças de classe e precarização da educação pública, elas estão comprometidas com as necessidades especificas da burguesia" (SIMÕES, 2017, p. 25). Com isso, as relações de intensa afinidade com o capital rentista não são surpresas em um país dependente das 
ações de países centrais e imperialistas, sendo "a emergência do dinheiro em estado puro como motor da vida econômica e social” (SANTOS, 2003, p. 38).

O espaço escolar é atingido pelos interesses que gerenciam os meios de produção, conforme aponta Santos (2003) e a tese de Simões (2017). Diante dessa afirmação, Milton Santos desenvolve o pensamento de que "o dinheiro regulador e homogeneizador agrava heterogeneidades e aprofunda as dependências. É assim que ele contribui para quebrar a solidariedade nacional, criando ou aumentando as fraturas sociais e territoriais e ameaçando a unidade nacional" (SANTOS, 2003, p. 104), levando-nos a crer que as realidades educacionais brasileiras foram e são constantemente colocadas em um limbo, havendo ora uma replicação de um ideal de dependência e prisão dos sujeitos ora uma "emancipação" de estudantes.

A educação no Brasil possui marcas profundas da falta de recursos e investimentos públicos, resultando em espaços sem condições básicas de infraestrutura, como Saviani (2010, p. 384) expõe: "municípios pobres tendem a ter um ensino pobre, municípios remediados, um ensino remediado, e municípios ricos, um ensino mais satisfatório". Essa disparidade leva a carências que atingem profissionais das escolas, assim como ao incentivo para a conclusão da formação de estudantes quanto ao desenvolvimento pleno por parte do restante da comunidade escolar. Além de implicar em uma precarização do ensino público e na transformação da educação em mercadoria, beneficiando o ensino privado que lucra com essas degradações (SIMÕES, 2017).

Enfocando com maior precisão nas políticas educacionais atuais, BNCC e Reforma do Ensino Médio, é preciso retornar aos anos neoliberais de desmonte da esfera pública (YANAGUITA, 2011). A década de 1990 possui entre seus marcos a aprovação da Lei de Diretrizes e Bases da Educação em 1996 (Lei no 9.394), que apresentava - naquele período - uma determinação para a criação de uma base comum nos currículos acrescida de uma parte diversificada; o artigo 26 expressa que: "os currículos do ensino fundamental e médio devem ter uma base nacional comum, a ser complementada, em cada sistema de ensino e estabelecimento escolar, por uma parte diversificada, exigida pelas características regionais e locais da sociedade, da cultura, da economia e da clientela" (BRASIL, 1996). Esse é um dos marcos de sustentação, senão o maior deles, para a intensa reconstrução do sentido de escola pública brasileira contemporânea.

Um segundo momento que embasa as leis atuais para educação é perceptível com a constituição dos Parâmetros Curriculares Nacionais (PCN) em 1998, quando são introduzidas as competências. Além de se buscar a inserção da interdisciplinaridade, há características alinhadas ao discurso tecnológico e de globalização que o texto apresenta (BRASIL, 1998). Outro ponto de inflexão que o PCN apresenta é a lógica do especialista competente, figura central na definição dos currículos (GIROTTO, 2017), todavia, sua presença minimizou a participação popular dos sujeitos da educação, sejam estes discentes, docentes, pais e mães, isto posto: "a escola e o professor passam a ser responsáveis pelo fracasso ou êxito de uma proposta curricular da qual pouco participaram no processo de elaboração" (ibidem, p. 429).

Uma compilação desses dois momentos apresentados compõe o cenário dos últimos anos para a educação brasileira. A BNCC é resultado de anos de estudo e estratégia para instrumentalização dos jovens (GIROTTO, 2017), suas sustentações legais são sólidas desde a Lei n. 9.394/1996 até o Plano Nacional de Educação (PNE) 2014-2024 por intermédio da meta 7.1 ${ }^{1}$. Ademais, o interesse permeia os atores hegemônicos das relações sociais, sendo assim, os investidores e apoiadores de seu desenvolvimento são grupos que se coalizaram, alinhando demandas do trabalho, do mercado e da indústria (GIROTTO, 2018), com destaque para o "Todos Pela Educação", composto por "catorze dos maiores grupos econômicos ligados à indústria, ao capital financeiro e ao agronegócio; e por dezoito parceiros, estes operadores, em especial nos sistemas municipais e estaduais de educação na disputa concreta do conteúdo, métodos e valores que interessam ao mercado" (RAMOS e FRIGOTTO, 2016, p. 35).

Essa ligação entre a esfera privada e o sistema público de ensino atesta o profundo alinhamento da educação com o capital. Como assevera Mészáros (2005), essa relação é reconhecida como temerosa ao desenvolvimento de jovens provenientes da classe trabalhadora. Afinal, esse ponto de articulação entre demandas mercadológicas e direito à educação coloca o espaço escolar em um limbo, em que existe de um lado a lógica de desigualdade e a mensuração e, de outro, um anseio emancipacionista e libertador, essa dualidade visivelmente paradoxal é postulada por Lacoste (1993) como sendo o ponto central de uma luta baseada em interesses pois, "ideias às quais posicionam o projeto educacional, obviamente, a serviço

\footnotetext{
1 O Plano Nacional de Educação (PNE) estabelece metas para melhoria da educação brasileira durante dez anos, dos quais a meta 7.1 trata do estabelecimento de uma base comum em termos curriculares para a educação básica em todo território nacional (BRASIL, 2014)
}

$\begin{array}{llllll}\text { Caminhos de Geografia } & \text { Uberlândia - MG } & \text { v. 22, n. 84 } & \text { dez/2021 } & \text { p. 14-24 } & \text { Página } 17\end{array}$


da economia capitalista, associando o trabalho educativo à formação de um 'novo tipo de homem'; a um 'novo tipo de trabalhador' '(SIMÕES, 2017, p. 221, grifos do autor).

A educação passa de um direito a uma ferramenta utilizada pelo neoliberalismo como forma de preservação das desigualdades e da formação de sujeitos alienados social e politicamente (ARAUJO JUNIOR, 2020), em que transformar o ensino e a escola em mercadoria é objetivo para manutenção da estrutura social, "daí a retórica presente no site do Banco Mundial, do Todos pela Educação e da Fundação Lehman que, dizendo-se profundamente preocupados com o futuro da educação pública no país, querem, de fato, garantir o avanço do capital sobre esta nova fronteira de valorização" (GIROTTO, 2017, p. 437). O que se vê é característico desde a década de 1990, apontado por Yanaguita (2011) através dos processos de privatizações das empresas estatais, o destaque de retrocesso merece ser dado ao governo de Fernando Henrique Cardoso, que realizou diversas vendas ao mercado capitalista durante seus dois mandatos (19952003).

Mudanças que impactaram positivamente a classe trabalhadora foram evidenciadas no período 2003-2016, com protagonismo dos governos de Lula e Dilma, cujos destaque é a criação do Fundo de Desenvolvimento para Educação Básica (FUNDEB) e o aumento progressivo dos investimentos (GENTILI; OLIVEIRA, 2013). Ainda assim, implementar uma educação deficitária e mutilada é projeto de uma elite brasileira que não reconhece como necessária a emancipação da classe trabalhadora e vê a educação como algo bancário e tecnicista, dito isto medidas reformistas à educação vinham sendo encaminhadas desde os governos petistas, como a primeira versão da BNCC de 2015 (CARTA CAPITAL, 2018). De todo modo, a partir do golpe de 2016 contra Dilma, medidas de Estado intensificaram a realidade educacional, através da Emenda Constitucional n. 95/ 2016, da Reforma do Ensino Médio (Lei n. 13.415/ 2017) e da Base Nacional Comum Curricular, em que o proletariado tem maximizada sua privação de emancipação e liberdade das amarras sociais, como propõe o sociólogo Florestan Fernandes: "não há reforma que concilie uma minoria prepotente a uma maioria desvalida" (1977, p. 245).

Dando voz ao movimento de oposição às políticas para a educação brasileira da atualidade, realizamos um apanhado informativo e elucidativo em torno da Base (BNCC). Sua natureza a aponta como um documento normativo e impositivo, além de ter havido uma falta de discussão com atuantes do chão escolar (cf. BRASIL, 2018, p. 581-587). Isto coloca em problemática a renovação efetiva do ensino, pois:

a renovação do ensino na sala de aula tem que acontecer, e para isso é necessário pensarmos junto com os professores (para sairmos da tentação do receituário pronto), pois na maioria das vezes nós gastamos em discussões teóricas e, no dia-a-dia da sala de aula, a prática é a mais tradicional e conservadora possível (CALLAI, 1995, p. 40-41).

A falta de comunicação e a rapidez nos processos de formação e desenvolvimento da BNCC são pautas levantadas e questionadas até o presente momento. Uma proposta de diretrizes curriculares como esta, realizada em um período de três anos e com apenas três versões corrigidas - no que diz respeito ao Ensino Médio - o que faz levantar pontos que contestam o documento nacional. As críticas aos documentos normativos estão presentes nos movimentos realizados por entidades como: Associação Nacional de Educação (ANPED), Associação de Geógrafos(as) Brasileiros(as) (AGB) e Associação Nacional de PósGraduação e Pesquisa em Geografia (ANPEGE), além das mais de 12 milhões de contribuições via plataforma online do Ministério da Educação (GARCIA NEIRA; ALVIANO JÚNIOR; FERREIRA DE ALMEIDA, 2016). Esses fatos confirmam que a sociedade se preocupa com a educação do Brasil e quer ser ouvida e atendida em seus anseios.

O ensino médio é uma das etapas da educação básica que mais sofre com as mudanças propostas, pois o que 0 atinge não é apenas a Base, mas também a sua reforma proposta por meio da Lei n. 13.415/ 2017. Quanto à lei supracitada que remodela o ensino médio, sua tramitação é desenvolvida baseada nos pilares de desmotivação do alunado, ranqueamento pelo Programa Internacional de Avaliação de Alunos (PISA) e outros exames de avaliação, evasão escolar e, por fim, carga de estudos exaustiva (FERRETI e RIBEIRO DA SILVA, 2017), pontos estes que se desenrolaram do planejado ao executado da Reforma:

A tramitação da MP 746/16 se fez no Congresso Nacional entre os meses de outubro de 2016 e fevereiro de 2017, em curto período (considerando o recesso do Legislativo Federal), no qual foram realizadas 11 audiências públicas. Nessas audiências, bem como na exposição de motivos da medida provisória, os argumentos em defesa de suas propostas carregam o viés pragmático presente nas DCNEM de 1998 e no PL 6.840/13: é preciso adequar a formação dessa juventude à lógica do mercado, pois apenas uma parte muito pequena dos concluintes da educação básica terá acesso à educação superior; é preciso reorganizar os currículos, dar ênfase ao preparo para os exames nacionais e internacionais. A MP 746/16 foi aprovada na Comissão Mista composta por deputados e senadores e com poucas mudanças tornou-se o Projeto de Lei de Conversão (PLV) 
34/2016. Após aprovação na Câmara dos Deputados e no Senado Federal, com algumas alterações, se tornou a Lei 13.415/17 (RIBEIRO DA SILVA e SCHEIBE, 2017, p. 27).

A partir do acesso ao documento legal, observamos alguns pontos que merecem indagações, como: o fatiamento do currículo, que é o que mais repercute; a desobrigação das treze disciplinas em substituição aos itinerários formativos, em forma transversal e interdisciplinar (BRASIL, 2018), que é reflexo de uma flexibilização da escola, como apontado por Saviani (2002); as desobrigatoriedades de currículo para o ensino médio, definindo "estudos e práticas de educação física, arte, sociologia e filosofia" (BRASIL, 2017), assim como a língua inglesa, todavia, o termo "ensino" só se direciona à Língua Portuguesa e à Matemática, colocando em desigualdade certos conhecimentos e ciências, como Biologia, Física, Geografia, História e Química, presentes apenas nos itinerários (BRASIL, 2018) como forma de aprofundamento e complementação da carga horária.

Fragmentar o currículo significa aprisionar a consciência (MARCUSE, 1982). Fato que faz surgir por meio desses itinerários formativos a falácia em relação à escolha voluntária das grandes áreas de conhecimento. A veracidade dessa falsa escolha é apresentada no quarto artigo da Lei $n^{\circ} 13.415$, "itinerários formativos, que deverão ser organizados por meio da oferta de diferentes arranjos curriculares, conforme a relevância para o contexto local e a possibilidade dos sistemas de ensino" (BRASIL, 2017, grifo nosso), assim, a oferta fica condicionada à infraestrutura e ao planejamento da escola. O próprio Documento Curricular para o estado de Goiás - etapa Ensino Médio (DC-GOEM) propõe "obrigatoriedade da oferta dos componentes curriculares Língua Portuguesa e Matemática, nas três séries do Ensino Médio, o ensino de Língua Estrangeira Moderna Inglês, ao longo da etapa, e a oferta de no mínimo dois itinerários formativos por unidade escolar" (GOIÁS, 2021, p. 126).

Outra problemática que merece atenção é o curso do itinerário "Formação Técnica e Profissional", que regulamenta o ensino técnico e ressalta um viés instrumentalista. Direcionado historicamente às camadas sociais populares e proletárias (RAMOS e FRIGOTTO, 2016), ferindo a emancipação dos (as) estudantes, o real processo de ensino-aprendizagem e preparando jovens, unicamente, para o mercado de trabalho. Esse projeto de tecnificação da juventude é contrário ao que se vê nos Institutos Federais que trazem a integração entre o curso técnico e a educação básica, além de ferir o pensamento de Pontuschka (2007, p. 112) de que "não é uma formação para o mercado de trabalho apenas, mas um jovem preparado para enfrentar as transformações cada vez mais céleres que certamente virão."

Esses movimentos calcificados na égide mercadológica e neoliberal atestam o conflito de interesses que há no campo educacional. Investimentos realizados por grupos empresariais (como "Todos pela Educação", Fundação Lehmann e outros) comprovam o que Girotto (2017) aponta como a ligação capitalista penetrando nos âmbitos escolares. As finalidades que insurgem com esses movimentos do capital corroboram para uma formação firmada na desigualdade, além de fomentarem convênios, parcerias e licitações em benefício de empresas do campo educativo, "se faz presente a mercantilização da educação básica, que passa a compor não apenas a definição das finalidades e concepções que orientam os processos formativos escolares, mas também o financiamento público para a oferta privada da educação" (RIBEIRO DA SILVA e SCHEIBE, 2017, p. 27).

Propor um ensino igualitário e homogêneo em âmbito nacional demonstra, ainda mais, os fundamentos da égide neoliberal firmada no ideal meritocrático. Isso assegura as desigualdades provenientes fundamentalmente - do capital, bem como da omissão do Estado enquanto assegurador das necessidades sociais e coletivas. Dessa forma, "a ideologia do mérito vem marcar a política liberal na educação para acentuar a fragmentação" (SIMÕES, 2017, p. 25), um ensino em igualdade deve ser concebido a partir de investimentos que, primeiramente, reduzam e mitiguem as desigualdades. Todavia, esses fomentos não têm existência comprovada na nova educação brasileira, como dito pelo governo federal (CASTILHO, 2017).

As pontuações ora levantadas subscrevem que a educação da classe trabalhadora e distante da lógica capitalista não é o objetivo. $O$ anseio é o melhoramento avaliativo em exames nacionais e internacionais, isto é, o ranqueamento no PISA, no IDEB e afins, dito isto, vemos a inserção das "competências e habilidades" fundadas na resolução de problemas e na solução pontual destes, bem como no pressuposto de saber-fazer, que a própria BNCC aponta como "aprendizagens essenciais estabelecidas" (BRASIL, 2018). O direito ao pensar em completude, criticamente e de modo dialético é retirado, transformando em um modo mnemônico, isto é, "o estudante é mais e mais adestrado para compreender e avaliar relações e possibilidades estabelecidas somente em referência às relações e possibilidades estabelecidas" (MARCUSE, 1982, p. 166), alicerçado na repetição e na memorização.

Questionar a BNCC e a Reforma do Ensino Médio é necessário para entendermos o quão perverso são seus discursos e o quanto se complementam. O temor é dedicado a toda educação básica, todavia, as ciências humanas são mais passíveis deste processo contemporâneo. Universalizar diversas ciências com

$\begin{array}{llllll}\text { Caminhos de Geografia } & \text { Uberlândia - MG } & \text { v. 22, n. 84 } & \text { dez/2021 } & \text { p. 14-24 } & \text { Página } 19\end{array}$


objetos de estudo específicos, ainda que afins, é descredibilizar o potencial científico e transformador que o conhecimento possui. Deste modo, retoma-se em Girotto $(2017 ; 2018)$ que critica a BNCC e a Reforma por serem instrumentos de descrédito à Educação e, sobretudo, à Geografia, visto que esta é de suma importância, pois: "o ensino de Geografia deve preocupar-se com o espaço nas suas multidimensões" (CASTROGIOVANNI, 2000, p. 12), assim, o entendimento daquilo que observo e vivo é o pulsar da Geografia. As percepções e análises se dão alicerçados nas indagações, diante disso, fazer Geografia é refletir para criar, sendo a escola o lócus da construção firmada na coletividade e na realidade (VESENTINI, 1994).

O que se vê ao facultar o ensino de Geografia e condensá-lo juntamente com demais ciências humanas é uma forma estratégica e perversa de domínio por meio da educação ante à sociedade, endossando a intencionalidade que a geografia escolar enfadonha e desinteressante proposta por Lacoste (1993) possui. Em que propor aos estudantes pensar por conta própria na busca por construir seu conhecimento pessoal, como adverte Vesentini (1999), se esvai. Para Couto (2016, p. 195), a BNCC deve primar por "reconhecer conteúdos do ensino no grupo de vivência dos alunos ou situar seus lugares em relação a processos espaciais mais gerais", mas o que se vê - através do autor - é uma dificuldade em empregar tal metodologia em um ensino de previsão e soluções objetivadas como metas.

Castrogiovanni (2000, p. 14, grifos do autor) afirma que "o trabalho espacial deve conter o sentimento de provocação dos 'porquês', 'para quês', 'para quem'. O 'quando' e o 'como' são indispensáveis no entendimento do processo", construindo, assim, uma Geografia que seja alimentada pela historicidade e fluída a depender dos conflitos que cercam o espaço, pois a importância do processo está atrelada à compressão do desenvolvimento do espaço. Isto confirma que "deve ensinar - ou melhor, deixar o aluno descobrir - o mundo em que vivemos, com especial atenção para a globalização e as escalas local e nacional, deve enfocar criticamente a questão ambiental e as relações sociedade/natureza" (VESENTINI, 1995, p. 16 apud CAVALCANTI, 1998, p. 23). A realidade e as dinâmicas da sociedade são decisivas para ensinar Geografia e para impulsionar discentes enquanto sujeitos sociais.

Por intermédio de Callai (2000), sínteses só surgem por meio de análises, sendo esta o motor da Geografia, por isso: "essa disciplina busca proporcionar ao aluno um 'novo olhar' sobre o seu contexto sociocultural. Para a Geografia, esse olhar está relacionado ao estudo do espaço" (RICHTER, 2011, p.16, grifos do autor). Deste modo, ensinar Geografia deve ser coletivo, democrático, interdisciplinar e dialético, pontos estes definidos por Cavalcanti (2012) como elementares na construção do saber geográfico, em que o cotidiano e a experiência sejam considerados no ambiente escolar e nas aulas de Geografia, transformando estudantes em sujeitos do/no mundo.

Os problemas inerentes para pensar a Geografia na BNCC, em especial para o Ensino Médio, estão em toda sua história - desde sua gênese. Couto (2016) destaca a dificuldade de conceituar e delimitar o que seria as ciências humanas, o que é relevante para elas e o que as une enquanto meios analíticos do conhecimento. A nebulosidade sobre isso é tamanha que confirma o tensionamento em torno do assunto (GIROTTO,2018). As múltiplas nuances perpassadas pela Geografia mostram o quão temeroso é o ataque das políticas educacionais atuais, em que despertar a consciência de jovens enquanto seres sociais, históricos e políticos deveria ser o objetivo central, é o último.

Iniciativas governamentais começaram a se desenvolver desde 2018 no estado goiano, como o Documento Curricular para a educação infantil e ensino fundamental do estado de Goiás (DC-GO), cuja aprovação se deu a partir de seminários realizados em diversos munícipios goianos, entre agosto e setembro de 2018, totalizando 40 encontros com dois momentos: o primeiro se dedicou à explanação geral sobre o DC-GO, seguido de discussões fragmentadas dos componentes curriculares. Estes eventos tinham duração de apenas um dia, das $8 \mathrm{~h}$ às $18 \mathrm{~h}$, demonstrando a despreocupação do governo do estado com as considerações de quem compõem o chão da escola, visto que o curto prazo de tempo não é suficiente para discutir um currículo estadual. Em contato com a Subsecretaria Regional de Educação, em Catalão-GO, a aprovação do DC-GO foi realizada em outubro de 2018 pelo Conselho Estadual de Educação do Goiás (CEE-GO).

Quanto ao ensino médio, o Documento Curricular para Goiás - Etapa Ensino Médio (DC-GOEM) estava em construção desde 2019 e teve sua publicação no início de 2021, após contribuição de mais de 49 mil membros da comunidade escolar (GOIÁS, 2021). As mudanças que o DC-GOEM propõem são afins com o Novo Ensino Médio e a BNCC, cuja ampliação de carga horária e ênfases de conhecimento são os principais objetivos. O DC-GOEM apresenta a pluralidade de estudantes que compõem a realidade escolar goiana no ensino médio, dos quais baseiam a proposta dos itinerários formativos interrelacionados em trilhas do conhecimento, sendo "organizados em 6 (seis) macro áreas: Meio Ambiente, Saúde, Cidadania e Civismo, Ciência e Tecnologia, Economia e Multiculturalismo. Sendo que as seis macros áreas estão

$\begin{array}{llllll}\text { Caminhos de Geografia } & \text { Uberlândia - MG } & \text { v. 22, n. } 84 & \text { dez/2021 } & \text { p. 14-24 } & \text { Página } 20\end{array}$


estruturadas em 15 (quinze) Temas Contemporâneos" (GOIÁS, 2021, p. 114). A Figura 1 a seguir demonstra a divisão:

Figura 1 - Quadro demonstrativo dos itinerários formativos e os temas transversais de conhecimento:

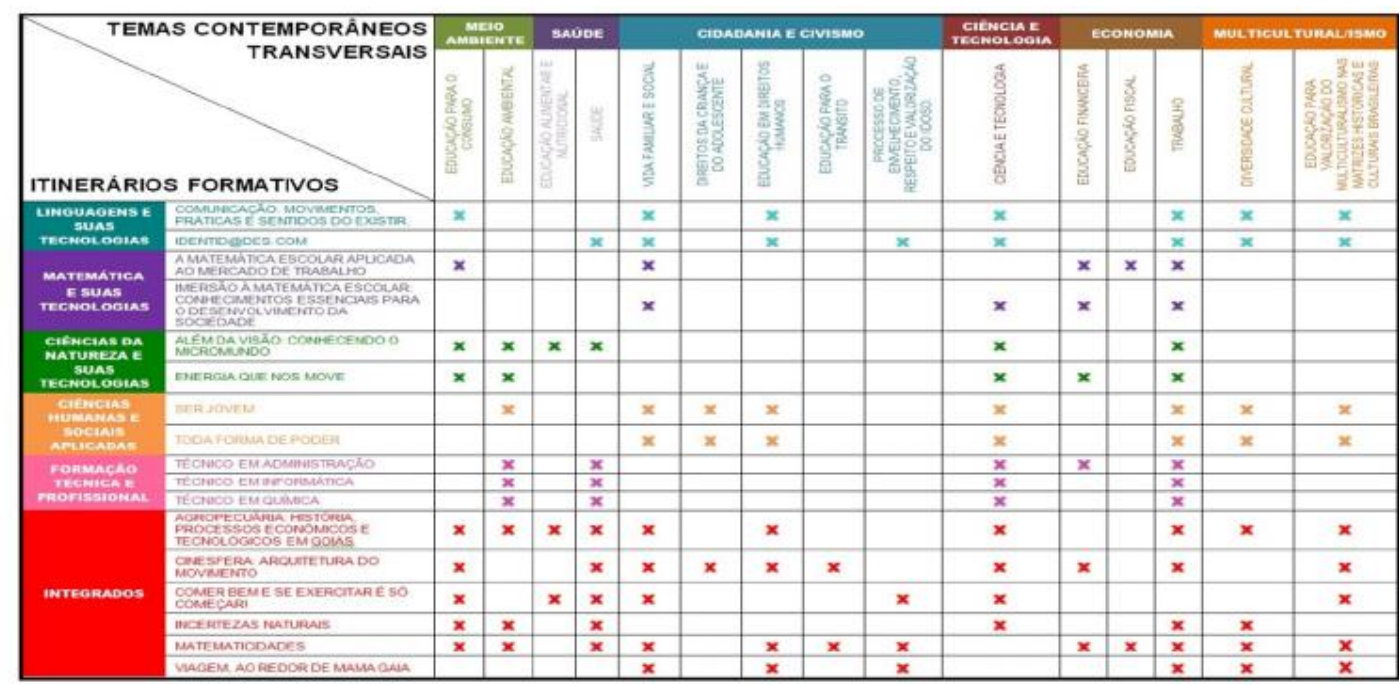

Fonte: Goiás (2021)

O DC-GOEM proposto trabalha de uma forma que para além das competências e habilidades expostas na BNCC-EM, há para cada área do conhecimento itinerários formativos que estão sintonizados com as trilhas do conhecimento, uma forma de caminho a ser traçado para efetiva aprendizagem (GOIÁS, 2021). Todavia, como apresentado no próprio documento a oferta de todos os itinerários formativos não é obrigatória, logo as 15 trilhas são facultadas de serem implementadas nas escolas goianas.

O Novo Ensino Médio tem sua implementação anunciada pelo Ministério da Educação e alinhada no estado de Goiás para ocorrer, em caráter normativo e progressivo para todo território nacional, em 2022 para as $1^{\text {a }}$ séries do Ensino Médio, em 2023 para as 2ª séries e fechando o ciclo em 2024 (BRASIL, 2021). Todavia, algumas experiências já estão ocorrendo em Goiás, como o próprio DC-GOEM expõe:

\begin{abstract}
Na rede estadual de educação de Goiás, todos/as os/as estudantes do Ensino Médio têm acesso a uma arquitetura curricular que contempla os componentes curriculares obrigatórios da formação geral básica, o componente curricular Projeto de Vida e componentes eletivos. Todas as turmas da primeira série, de período parcial, que não dependem do transporte escolar municipal, iniciaram no ano letivo de $2020 \mathrm{com}$ a matriz curricular que contempla a flexibilização por meio de escolha de componentes curriculares eletivos e do componente curricular Projeto de Vida. A partir da segunda série do Ensino Médio, deverão escolher também as trilhas de aprofundamento que melhor se adequem aos seus interesses e a seu PV (GOIÁS, 2021, p. 128).
\end{abstract}

Outro exemplo visível no território goiano e em todo Brasil foi noticiado pelo Portal Metrópoles, é o caso do Sistema SESI/SENAI, através de um projeto piloto de aplicação do Novo Ensino Médio desenvolvem, "desde o ano passado, um material escolar autoral, atendendo todas as etapas da educação básica, além do ensino de jovens e adultos" (FILIZOLA, 2021, online). De todo modo, realidades mais concretas do novo formato de ensino médio e seus efeitos serão perceptíveis quando sua aplicabilidade for obrigatória, em 2022, sobretudo nas escolas públicas.

\title{
CONSIDERAÇÕES FINAIS
}

Entende-se que o Estado, em suas atribuições, possui a função de cumprir com os anseios cidadãos e a educação é uma dessas vertentes que cabe a ele seu cuidado, gestão e funcionamento, todavia, vivemos em uma sociedade gerida e submissa ao sistema que tem como motor o dinheiro, isto é, o capitalismo. No desenvolvimento da pesquisa evidenciar a ligação entre capital e educação foi fundamental para entendermos o atual modelo proposto para o Brasil em termos escolares. Diante disso, ter a educação em harmonia com o capital é "produzir uma conformidade ou 'consenso' quando for capaz, a partir de dentro e 
por meio dos seus próprios limites institucionalizados e legalmente sancionados" (MÉSZÁROS, 2005, p. 45, grifos do autor).

A materialização do campo educativo atual é o que Mészáros (2005) nos apontava como uma educação capitalista, em que as desigualdades são reproduzidas com embasamentos concernentes ao Estado, ainda que sua função devesse ser a de reparar as disparidades sociais. As políticas em voga, BNCC e Reforma do Ensino Médio, são a personificação do capital na esfera pública de educação, portanto, sua legalidade e implementação são a prova de um ensino que corrobora para o aprisionamento de sujeitos, a limitação no pensar crítico e social, além de firmar o ideal de meritocracia.

Essa homogeneidade ideal apenas fomenta o enfraquecimento das regionalidades e particularidades que caracterizam o espaço geográfico e os lugares, diante disso, a lógica globalizante e homogeneizadora impera, pondo fim à diversidade, como assevera Santos (2003). Para pensarmos em uma superação das desigualdades e na melhoria do ensino é preciso que a efetividade do Estado, enquanto esfera de intervenção, seja verdadeira, primando pelas particularidades de cada região, de cada estado e de cada escola, para tal, ouvir os protagonistas do chão da escola é fundamental (CALLAI, 1995).

Reduzir conteúdos e disciplinas é menosprezar o verdadeiro conhecimento, que deveria ser amplo, baseado na realidade do aluno e pautado em uma leitura social, crítica e política. É necessário primar por um pensar que seja emancipador, libertando estudantes e dando uma nova ótica quanto ao desenvolvimento social (HOOKS, 2013). Mas, o que vemos com tais políticas é negação do desenvolvimento intelectual de Young (2011), isto pois a solução de pontualidades, visíveis em rankings e nas proposições de competências, direciona a educação contemporânea. O que corrobora para enxergarmos a escola e o currículo enquanto um espaço de conflitos e contradições (GIROTTO, 2017; 2018), tanto de interesses quanto de poder, portanto, devemos enxergar o lado político-ideológico dessas perversidades.

Postular aquilo que deve ser prioridade e o que é complementaridade ao alunado é estar conivente com uma formação fragmentada e deficitária; a retirada da ciência geográfica é um dos resultados disso. Pontuschka (2007) afirma que não podemos formar futuros cidadãos sem poder de criticidade e reflexão, pois o desenvolvimento de um olhar espacial em outra perspectiva - agora mais analítica e criteriosa - é um dos pressupostos para se tornar um(a) trabalhador(a) consciente das desigualdades, das opressões e das imposições originárias do sistema capitalista. Concluindo, Mészáros (2005, p. 47) há tempos expunha que: "o que existia antes de tais reformas será restabelecido, mais cedo ou mais tarde, devido ao absoluto fracasso em desafio, por meio de uma mudança institucional isolada, a lógica autoritária global do próprio capital."

\section{AGRADECIMENTOS}

A realização deste artigo, bem como de demais resultados desta pesquisa, foi possível através do apoio financeiro do Conselho Nacional de Desenvolvimento Científico e Tecnológico (CNPq) em parceria com a Universidade Federal de Goiás (UFG) pela concessão de bolsas de iniciação científica. Os agradecimentos se estendem aos que contribuíram de alguma forma à pesquisa, entre tantos, ao Grupo de Estudos e Pesquisas Interdisciplinares em Gênero, Cultura e Trabalho - DIALOGUS.

\section{REFERÊNCIAS}

ARAUJO JUNIOR, Aloysio Marthins de. Estado Neoliberal e políticas educacionais: discutindo sobre a formação de professores de geografia no Brasil. Giramundo, Rio de Janeiro, v. 7, n. 14, p. 29-41, 2020.

BRASIL. Constituição da República Federativa do Brasil. Brasília: Diário Oficial da União, 1988.

Lei no 9.394, de 20 de dezembro de 1996. Estabelece as diretrizes e bases da educação nacional. Brasília, DF: Diário Oficial da União, 1996.

. Conselho Nacional de Educação. Câmara da Educação Básica. Resolução CNE/CEB no 3, de 26 de junho de 1998. Institui as Diretrizes Curriculares Nacionais para o Ensino Médio. Brasília, DF: Diário Oficial da União, 1998.

Lei no 13.005, de 25 de junho de 2014. Aprova o Plano Nacional de Educação - PNE e dá outras providências. Brasília, DF: Diário Oficial da União, 2014.

Medida Provisória MPV 746/2016. Brasília, DF: Diário Oficial da União, 2016. 
Emenda Constitucional no 95, de 15 de dezembro de 2016. Altera o Ato das Disposições Constitucionais Transitórias, para instituir o Novo Regime Fiscal, e dá outras providências. Brasília, DF: Diário Oficial da União, 2016.

Lei no 13.415, de 16 de fevereiro de 2017. Altera a Leis no 9.394, de 20 de dezembro de 1996 , que estabelece as diretrizes e bases da educação nacional. Brasília, DF: Diário Oficial da União, 2017. Ministério da Educação. Base Nacional Comum Curricular. Brasília, DF: MEC, 2018.

. Ministério da Educação. Portaria no 521, de 13 de julho de 2021. Institui o cronograma nacional de implementação do Novo Ensino Médio. Brasília, DF: Diário Oficial da União, 2021.

CALLAI, Helena Copetti. A formação do professor de Geografia. Boletim Gaúcho de Geografia, n. 20, Porto Alegre, dez. 1995.

. Helena Copetti. Estudar o lugar para compreender o mundo. In: CASTROGIOVANNI, A. C. (org.). Ensino de Geografia: práticas e textualizações no cotidiano. Porto Alegre: Mediação, 2000.

CARTA CAPITAL. Base Nacional Comum e a defesa da centralização curricular nas candidaturas ao Planalto. São Paulo, 13 set. 2018. Disponível em: https://www.cartacapital.com.br/opiniao/basenacional-comum-e-a-defesa-da-centralizacao-curricular-nas-candidaturas-ao-planalto. Acesso em: 27 jul. 2021.

CASTILHO, Denis. Reforma do Ensino Médio: desmonte na educação e inércia do enfrentamento retórico. Revista Eletrônica de Diálogo e Divulgação em Geografia, n. 4, vol. 1, 2017.

CASTROGIOVANNI, Antonio Carlos. Apreensão e compreensão do espaço geográfico. In: ( org.). Ensino de Geografia: práticas e textualizações no cotidiano. Porto Alegre: Mediação, 2000.

CAVALCANTI, Lana Souza. Geografia, escola e construção de saberes. Campinas, SP: Papirus, 1998. . O ensino de geografia na escola. Campinas, SP: Papirus, 2012.

COUTO, Marcos Antônio Campos. Base Nacional Comum Curricular - BNCC. Componente curricular: Geografia. Revista ANPEGE, v.12, n.19, p.183-203, 2016.

FERNANDES, Florestan. A sociologia no Brasil. Petrópolis: Vozes, 1977.

FERRETI, Celso João; RIBEIRO DA SILVA, Mônica. Reforma do ensino médio no contexto da medida provisória n. 746/2016: estado, currículo e disputas por hegemonia. Revista Educação e Sociedade, Campinas, v. 38, n. 139, 2017.

FILIZOLA, Paula. Entenda como o novo ensino médio amplia chances de emprego para jovens. Metrópoles, 29 jun. 2021.

FREIRE, Paulo. Pedagogia do oprimido. Rio de Janeiro: Paz e Terra, 2005.

GARCIA NEIRA, Marcos; ALVIANO JÚNIOR, Wilson; FERREIRA DE ALMEIDA, Debérson. A primeira e segunda versões da BNCC: construção, intenções e condicionantes. EccoS Revista Científica, São Paulo, n. 41, 2016.

GENTILI, Pablo; OLIVEIRA, Dalila Andrade. A procura da igualdade: dez anos de política educacional no Brasil. In: SADER, Emir (org.). 10 anos de governos pós-neoliberais no Brasil: Lula e Dilma. São Paulo: Boitempo; Rio de Janeiro: FLACSO, 2013

GIROTTO, Eduardo Donizeti. Dos PCNS a BNCC: O ensino de Geografia sob o domínio neoliberal. Revista GEO UERJ, n. 30, Rio de Janeiro, 2017.

Eduardo Donizeti. Entre o abstracionismo pedagógico e os territórios de luta: a base nacional comum curricular e a defesa da escola pública. Revista Horizontes, v. 36, n. 1, 2018.

GOIÁS. Conselho Estadual de Educação - CEE/GO. Documento Curricular para Goiás. Goiânia: CEE/GO, 2018.

. Conselho Estadual de Educação - CEE/GO. Documento Curricular para Goiás - etapa Ensino Médio. Goiânia: CEE/GO, 2021.

HOOKS, Bell. Ensinando a transgredir: a educação com prática de liberdade. São Paulo: WMF Martins Fontes, 2013. 
LACOSTE, Yves. A Geografia, isso serve, em primeiro lugar, para fazer a guerra. Campinas, SP: Papirus, 1993.

MARCUSE, Herbert. A ideologia da sociedade industrial. O homem unidimensional. Rio de Janeiro: Zahar, 1982.

PÊSSOA, Vera Lúcia Salazar. GEOGRAFIA E PESQUISA QUALITATIVA: um olhar sobre o processo investigativo. Revista Geo UERJ, n. 23, v. 1, 2012.

PONTUSCHKA, Nídia Nacib. A geografia: pesquisa e ensino. In: CARLOS, Ana Fani. (org.). Novos rumos da Geografia. São Paulo: Contexto, 2007.

MÉSZÁROS, István. A educação para além do capital. São Paulo: Boitempo, 2005.

RAMOS, Marise Nogueira; FRIGOTTO, Gaudêncio. Medida Provisória 746/2016: a contra-reforma do ensino médio do golpe de estado de 31 de agosto de 2016. Revista HISTEDBR On-line, Campinas, $n$. 70, 2016.

RIBEIRO DA SILVA, Mônica; SCHEIBE, Leda. Reforma do ensino médio: Pragmatismo e lógica mercantil. Revista Retratos da Escola, Brasília, v. 11, n. 20, 2017.

RICHTER, Denis. O mapa mental no ensino de Geografia: concepções e propostas para o trabalho docente. São Paulo: Cultura Acadêmica, 2011.

SANTOS, Milton. Por uma geografia nova. São Paulo: EDUSP, 1978.

. Milton. Por uma outra globalização: do pensamento único à consciência universal. Rio de Janeiro: Record, 2003.

SAVIANI, Dermeval. Apresentação. In: GASPARIN, João Luiz. Uma didática para a pedagogia histórico-crítica. Campinas: Autores Associados, 2002.

Sistema Nacional de Educação articulado ao Plano Nacional de Educação. Revista Bras. de Educação, Rio de Janeiro, v. 15, n. 44, 2010.

SIMÕES, Roberto Alves. A ação criminosa das ONGs - A privatização da escola pública. Rio de Janeiro: Consequência, 2017.

VESENTINI, José Willian. Geografia crítica e ensino. In: OLIVEIRA, Ariovaldo Umbelino. (org.). Para onde vai o ensino de Geografia?. São Paulo: Contexto, 1989.

José Willian. Ensino de Geografia e luta de classes. In: OLIVEIRA, Ariovaldo Umbelino. (org.). Para onde vai a Geografia?. São Paulo: Contexto, 1994.

José Willian. Educação e ensino de geografia: instrumentos de dominação e/ou libertação. In: CARLOS, Ana Fani. (org.). Geografia na sala de aula. São Paulo, Contexto, 1999.

YANAGUITA, Adriana Inácio. As políticas educacionais no Brasil nos anos 1990. In: Simp. Bras. e II Congr. Ibero-Americano de Pol. e Adm. da Educação. São Paulo, 2011. Anais... São Paulo, 2011.

YOUNG, Michael. O futuro da educação em uma sociedade do conhecimento: a defesa radical de um currículo disciplinar. Revista Bras. de Educação, v. 16 n. 48, 2011.

Recebido em: 30/07/2020

Aceito para publicação em: 02/10/2021 